\title{
The effect of the District Heating Return Temperature Reduction on Flue Gas Condenser Efficiency
}

\author{
Kertu LEPIKSAAR ${ }^{1 *}$, Anna VOLKOVA ${ }^{2}$, Pavel RUSELJUK ${ }^{3}$, Andres SIIRDE ${ }^{4}$ \\ 1, 2, ${ }^{4}$ Tallinn University of Technology, Ehitajate tee 5, 19086 Tallinn, Estonia \\ ${ }^{3}$ AS Narva Soojusvõrk, Oru tn 2, 20203 Narva, Estonia
}

\begin{abstract}
The use of flue gas condensers proved to be effective in increasing boiler efficiency and achieving primary energy savings. The transition to the $4^{\text {th }}$ generation district heating will lead to temperature reduction in district heating networks. The aim of this study is to determine the effects of the reduction in the district heating return temperature on flue gas condenser efficiency. Different DH return temperatures and fuel moisture contents were examined, and a calculation model was created. The results show that a reduction in district heating return temperature can lead to an increase in heat recovery through the flue gas condenser. Primary energy savings were estimated based on the amount of heat recovered.
\end{abstract}

Keywords - CHP (combined power and heat); condensation; 4GDH $\left(4^{\text {th }}\right.$ generation district heating); heat- and mass transfer; heat recovery; PES (primary energy savings)

\begin{tabular}{ll}
\hline Abbreviations & \\
$4 \mathrm{GDH}$ & $4^{\text {th }}$ Generation District Heating \\
$\mathrm{CHP}$ & Combined Heat and Power \\
DH & District Heating \\
FGC & Flue Gas Condenser \\
NCV & Net Calorific Value \\
PES & Primary Energy Savings
\end{tabular}

Parameters

$a$

Excess air coefficient

A Heat transfer surface area of the flue FGC $\mathrm{m}^{2}$

$b \quad$ Flue gas consumption $\mathrm{kg} / \mathrm{s}$

$\begin{array}{cll}c_{p} & \text { Specific heat at constant pressure } \quad \mathrm{J} /(\mathrm{kg} \cdot \mathrm{K})\end{array}$

d Diameter m

g Gravitational acceleration $\mathrm{m} / \mathrm{s}^{2}$

$G_{\text {return }} \quad$ District heating return mass flow $\mathrm{kg} / \mathrm{s}$

$h \quad$ Heat transfer coefficient $\quad \mathrm{W} /\left(\mathrm{m}^{2} \cdot \mathrm{K}\right)$

$H \quad$ Height of heat transfer surface m

* Corresponding author.

E-mail address: kertu.lepiksaar@taltech.ee

(C)2020 Kertu Lepiksaar, Anna Volkova, Pavel Ruseljuk, Andres Siirde.

This is an open access article licensed under the Creative Commons Attribution License (http://creativecommons.org/

licenses/by/4.0), in the manner agreed with Sciendo. 


\begin{tabular}{|c|c|c|}
\hline$j$ & Diffusion flow & $\mathrm{kg} /\left(\mathrm{s} \cdot \mathrm{m}^{2}\right)$ \\
\hline$k$ & Thermal conductivity & $\mathrm{W} /(\mathrm{m} \cdot \mathrm{K})$ \\
\hline$l$ & Flow lenght & $\mathrm{m}$ \\
\hline$m$ & Mass fraction per $1 \mathrm{~kg}$ of consumed fuel & $\mathrm{kg} / \mathrm{kg}$ \\
\hline$M$ & Molar mass & $\mathrm{kg} / \mathrm{mol}$ \\
\hline$N u$ & Nusselt number & - \\
\hline$P E S_{I M W h}$ & Primary energy savings per $1 \mathrm{MWh}$ generated & $\mathrm{MWh} / \mathrm{MWh}$ \\
\hline$P E S_{\text {inc }}$ & $\begin{array}{l}\text { Increase in primary energy savings through } \mathrm{DH} \\
\text { return temperature reduction }\end{array}$ & $\mathrm{MWh} /(\mathrm{MWh} \cdot \mathrm{K})$ \\
\hline $\operatorname{Pr}$ & Prandtl number & - \\
\hline$q$ & Heat flux & $\mathrm{W} / \mathrm{m}^{2}$ \\
\hline Qair & Heat of combustion air & $\mathrm{W}$ \\
\hline$Q_{\text {comp }}$ & Heat required for heating fuel components in the boiler & $\mathrm{W}$ \\
\hline$Q_{\text {cond }}$ & Total recoverable heat from condensation & $\mathrm{W}$ \\
\hline$Q_{\text {latent }}$ & Heat from water vapour condensation & $\mathrm{W}$ \\
\hline$Q_{N C V}$ & Net calorific value of fuel & $\mathrm{MJ} / \mathrm{kg}$ \\
\hline$Q_{\text {rec.heat }}$ & Amount of heat recovered & $\mathrm{W}$ \\
\hline$Q_{\text {sensible }}$ & Cooling heat from non-condensable gases & $\mathrm{W}$ \\
\hline$r$ & Heat of condensation & $\mathrm{J} / \mathrm{kg}$ \\
\hline$r d$ & Relative difference & - \\
\hline $\operatorname{Re}$ & Reynolds number & - \\
\hline$t_{\text {return }}$ & District heating return temperature, & ${ }^{\circ} \mathrm{C}$ \\
\hline$\delta$ & Thickness & $\mathrm{m}$ \\
\hline$\Delta t$ & Temperature difference & $\mathrm{K}$ \\
\hline$\Delta t_{\log }$ & Logarithmic mean temperature difference & $\mathrm{K}$ \\
\hline$\eta$ & Efficiency & \\
\hline$v$ & Kinematic viscosity & $\mathrm{m}^{2} / \mathrm{s}$ \\
\hline \multicolumn{3}{|c|}{ Subscripts } \\
\hline calc & Calculated & \\
\hline$c y l$ & Cylinder heat transfer surface & \\
\hline$D$ & Diffusion & \\
\hline$d p$ & Dew point & \\
\hline$d r y$ & Flow sans moisture & \\
\hline$f g$ & Contained in flue gases & \\
\hline$F G C$ & Flue gas condenser & \\
\hline flat & Flat heat transfer surface & \\
\hline flow & Prandtl number based on flow temperature & \\
\hline meas & Measured & \\
\hline$N u$ & According to Nusselt's analogy & \\
\hline
\end{tabular}




\begin{tabular}{|ll|}
\hline$t h$ & Thermal \\
$w$ & Water \\
wall & Prandtl number based on wall temperature \\
\hline
\end{tabular}

\section{INTRODUCTION}

There are many different ways to achieve savings in terms of primary energy consumption. District heating improvements hold great potential for a subsequent increase in energy efficiency. The European Union's energy policy promotes district heating (DH) and combined heat and power (CHP) generation in accordance with the Directive 2012/27/EU of the European Parliament and of the Council of 25 October 2012. The Directive states that energyefficient DH is a DH system that uses at least $50 \%$ renewable energy, $50 \%$ waste heat, $75 \%$ cogenerated heat, or $50 \%$ a combination of such energy and heat [1]. One option for improving heat production efficiency is to install flue gas condensers (FGC) to recover waste heat from flue gases.

The transition to the $4^{\text {th }}$ generation district heating (4GDH) will lead to significant energy savings since the required temperatures are low and low-grade energy sources can be used. Volkova et al. studied the dynamics of the transition process towards the 4GDH and identified the main requirements that must be met for the successful transition [2]. The main objectives are:

- Use of renewable (non-fuel) energy;

- Low network heat loss;

- Integration of CHP plants;

- Thermal energy storage integration;

- Intelligent metering.

As can be seen from the key requirements, the transition will lead to the reduction of DH temperatures, both supply and return. The decrease of DH flow temperatures has several benefits for CHPs, including increased electricity production and lower heat losses and pumping costs [3].

The impact of low-temperature $\mathrm{DH}$, including low return temperatures, can be assessed in many ways. A life-cycle assessment of low-temperature district heating was conducted in [4], and it was determined that solar photovoltaic technology should be introduced to decrease the environmental impact of DH. Integration of low temperature heat sources, such as solar energy [5], [6] seawater or sewage water [7] has an impact on return temperature reduction. Exergy analysis method for thermal networks was described in [8] which can be also used to evaluate DH environmental impact.

Market competitiveness of heat largely depends on the temperature of the return network water. The return DH temperature is a parameter that cannot be controlled by the operator only; it is regulated via the operating mode of the entire DH system, including heat sources, network and consumer [2]. The technical state of the consumer heat supply systems and the organisation of their operation have a great influence on the temperature of the return network water. There are numerous reasons for this, from errors in system design, heat exchangers, circulation pumps, automatic regulating fittings, heat energy meters and automatic control devices to various human factors and each has individual capabilities.

The design of heating devices in buildings: when space heating is done by radiators, the heat transfer surface area is rather small compared to underfloor heating, which requires lower 
temperatures than radiator heating due to larger heat transfer surface areas [9]. Improper management of heating substations in buildings could also cause high temperatures in $\mathrm{DH}$ [10]. When other heat sources are used simultaneously with DH, it can also affect DH return temperatures. Parallel consumption was studied in [11]. Due to the fact that there is additional heat in the DH system, the return temperature of the DH network will be higher in the case of parallel consumption than without.

There are different ways to reduce return temperature from the consumer's side, such as refurbishment of older buildings and construction of new low-energy buildings [12]. However, housing is a rather slow process that can last for decades. When new lowtemperature consumers are added to the network using the energy-cascade method or any other method that promotes the use of low-temperature heating sources, it also helps reduce the return temperature. It is possible that the DH sector will go through a transition period where different technical solutions will be implemented simultaneously [13].

Under modern economic conditions, the reduction of the return temperature is not so much a technical issue, as it is an economic one. However, the problem of the DH return temperature reduction is very complex and cannot be solved quickly, because there are a lot of consumers, and each has individual capabilities. Consumers should be motivated to reduce return temperature. There are various economic measures that can affect consumer behaviour. One of the measures is a tariff system which was discussed in [14]. Another solution is to introduce multi-component rates with a bonus-malus component based on the return temperature, as for example in DH of Copenhagen, Stockholm and Saclay [15]. Fines paid for increased return temperature can motivate consumers. For example, in the Narva DH system (Estonia), the deviation of the return water temperature from the set value was recalculated for those consumers who exceeded the temperature. To compensate for the temperature in heat energy, it was necessary to increase the amount of water supplied to the DH network and introduce fines for consumers in the case the return temperature was too high. This forced most consumers to set up their own heating substations, and as a result, the DH water consumption rate decreased significantly in these heating systems [16].

Total energy cost savings in buildings can also prove to be motivating for consumers. The correlation between the decrease in energy costs and DH temperature reduction was examined in [17].

In recent years, $\mathrm{FGC}$ has been often used to increase the efficiency of a CHP or boiler plant. FGC can improve the efficiency of both the heating and CHP plants. FGC improves efficiency by recovering latent and sensible heat from flue gases and water vapours. FGC provides significant heat recovery when using fuels with high moisture content. The proportion of heat recovery in the total amount of heat supplied can be up to $30 \%$, increasing total plant efficiency by up to $15 \%$ [18]. An experimental study on the best FGC operational regime for small-scale boilers was conducted in [19], examining different water flow regimes while measuring moisture content of flue gases before and after fog unit and heat recovery.

Major factors that influence the proportion of FGC heat recovery include fuel moisture content, condensing temperature, fuel composition and flue gas temperature [18]. There are also other factors that affect mainly heat and mass transfer in FGC. These factors include flue gas flow velocity and regime (laminar or turbulent) and the construction of FGC. FGC efficiency is also studied in [20] and [21]. The method proposed in [20] was designed for heat and mass transfer in tubular FGC. In [21], different configurations for combined-cycle power plant to recover heat from flue gases were examined.

Fuel moisture content also affects temperature in boilers. Higher moisture content means that more energy must be used to evaporate the moisture that is introduced to the boiler with 
the fuel. High moisture content reduces fuel net calorific value (NCV) $(\mathrm{MJ} / \mathrm{kg})$ and flame temperature in the boiler. It is important that the temperature in the boiler does not exceed the temperature limits, as it may damage the boiler. FGC efficiency can be used as an indirect method for estimating fuel moisture content. Striūgas et al. proposed a methodology for assessing fuel moisture content based on the efficiency of FGC [22].

When FGC is not used, too high moisture content in the fuel can be considered as loss of efficiency. Typically, woodchip moisture content ranges anywhere from $30 \%$ to $50 \%$. When the moisture content exceeds $87.1 \%$, the lower calorific value is negative, and it is impossible to obtain any useful heat without condensing water vapour in flue gases.

This study explores the impact of the return temperature reduction on FGC by creating FGC efficiency and heat recovery models based on different fuel moisture values and DH return temperature values. Since FGC is most beneficial for high-moisture fuels, woodchips were chosen as fuel. However, the model is also applicable to other types of fuel. FGC heat recovery potential based on the DH return temperature was estimated using different fuel moisture content values. To calculate FGC efficiency and primary energy savings (PES) potential for different DH return temperatures, the most common fuel moisture content value was used.

A mathematical model was created in MS Excel for theoretical analysis. To validate the model, the theoretical results were compared with the actual measurements from the Mustamäe CHP plant (Mustamäe Koostootmisjaam), which uses woodchips as fuel.

\section{METHOD}

A diagram of all model components and system parameters is available in Appendix 1.

A scheme for mathematical tool described in this method is shown in Appendix 2.

The model for the theoretical analysis was created in MS Excel in accordance with the following methodology which is added as Appendix 3. The model can be applied to any CHP and/or boiler plant that uses any type of flue gas condenser.

In practice, $100 \%$ efficiency is unrealistic (according to gross calorific value). Heat and mass transfer aspects must also be considered, since not all latent heat can be recovered even if flue gases are cooled down to ambient temperature. Some heat recovery losses are caused by heat and mass transfer effects that can be considered when designing an FGC.

FGC can theoretically be viewed as a heat exchanger in which one of the heat flows has a phase transition, while heat transferred in the process is equal to recoverable sensible and latent heat, which is summed as $Q_{\text {cond }}(\mathrm{W})$. Flue gas is heat supplying flow and heat consuming flow is district heating return water that is returning to the boiler and can be preheated with the FGC-recovered heat. $Q_{\text {cond }}(\mathrm{W})$ can be calculated as follows (Eq. (1)):

$$
Q_{\text {cond }}=Q_{\text {sensible }}+Q_{\text {latent }} \text {, }
$$

where

$$
Q_{\text {sensible }}=m_{f g, g r y} \cdot\left(c_{p, f g 1, d r y} \cdot t_{f g}-c_{p, f g 2, d r y} \cdot t_{r e t u r n}\right) \cdot b
$$

and

$$
Q_{\text {latent }}=\left[m_{f g 1, H 2 O} \cdot\left(c_{p 1, H 2 O} \cdot t_{f g}+r_{1}\right)-m_{f g 2, H 2 O} \cdot\left(c_{p 2, H 2 O} \cdot t_{\text {return }}+r_{2}\right)\right] \cdot b .
$$


In Eq. (1), sensible heat $Q_{\text {sensible }}$ (W) (Eq. (2)) is the heat that is released by cooling noncondensable gases. Latent heat $Q_{\text {latent }}$ (W) (Eq. (3)) is the heat that is released by cooling and condensing water vapours in flue gases. In Eq. (2) and (3), index ' 1 ' refers to the FGC entering flow, and index ' 2 ' to the outgoing flow. Index ' $d r y$ ' refers to dry, moisture-free flue gases. To consider the exact amount of condensation heat, fuel consumption $b(\mathrm{~kg} / \mathrm{s})$ must also be considered, as it is done in Eq. (2) and Eq. (3). Since the specific heat of noncondensable gases is quite small compared to the sum of the specific heat of water and condensation heat, the proportion of sensible heat in total recoverable heat $Q_{\text {cond }}$ is approximately $30 \%$, but this depends on the moisture content $m_{\mathrm{H} 2 \mathrm{O}}(\mathrm{kg} / \mathrm{kg})$ of the fuel. When the moisture content is higher, the proportion of sensible heat in recoverable heat is smaller.

The amount of water vapours entering the FGC $m_{f g, l, H 2 O}(\mathrm{~kg} / \mathrm{kg})$ depends on fuel composition and moisture content. If flue gas moisture content is not measured, then it can be calculated stoichiometrically taking excess air coefficient $a$ into account. The excess air coefficient $a$ shows how much extra air is supplied to the boiler for combustion, if $a=1$, then the amount of combustion air is minimal, which is necessary for complete combustion. If $a>1$, then some extra air was introduced to the boiler, resulting in oxygen $\left(\mathrm{O}_{2}\right)$ content found in flue gases. When $a=1$, then all oxygen from the incoming air should be used up, and flue gases should not contain any oxygen. Usually, the necessary excess air coefficient of a boiler is constant and is indicated in the boiler manual. Typically, the excess air coefficient $a$ is about $1.05 \ldots 1.15$ [23].

The amount of flue gas can also be determined using a method described in DIN EN 12952-15 [24]. The standard proposes a slightly different approach, using numerical constants and special methods for various types of fuels.

In order to determine the amount of dry flue gas, $m_{f g, d r y}$ and water vapour $m_{f g l, H 2 O}$, the following calculations (Eq. (4)-Eq. (9)) must be performed. The analytical content of the dry fuel should also be known. Typically, the analytical components that ultimately turn into dry flue gases are carbon (C) and sulphur (S). As for the burning of woodchips, the temperature is too low for nitrogen $(\mathrm{N})$ to oxidize, so it can be viewed as inertial [25]. Since the sulphur content in woodchips is marginal (less than $0.5 \%$ ), there is no need to take it into account for FGC calculations [26]. Therefore, dry flue gases mainly contain carbon dioxide $\left(\mathrm{CO}_{2}\right)$, nitrogen $\left(\mathrm{N}_{2}\right)$ from fuel and nitrogen that entered the boiler with the air and excess oxygen $\left(\mathrm{O}_{2}\right)$, which was not used for combustion.

According to stoichiometry and the excess air coefficient, the amount of $\mathrm{CO}_{2} m_{f g, C O 2}(\mathrm{~kg} / \mathrm{kg})$ emitted by burning $1 \mathrm{~kg}$ of fuel is calculated by Eq. (4).

$$
m_{f g, \mathrm{CO} 2}=\left(1-m_{\mathrm{H} 2 \mathrm{O}}\right) \cdot m_{c, d r y} \cdot \frac{M_{\mathrm{CO} 2}}{M_{C}}+\frac{m_{O 2} \cdot 0.046 \%}{23.1 \%},
$$

where $m_{H 2 O}$ is fuel moisture content $(\mathrm{kg} / \mathrm{kg})$, and $m_{c, d r y}$ is carbon content in dry fuel $(\mathrm{kg} / \mathrm{kg})$. $0.046 \%$ refers to the mass fraction of $\mathrm{CO}_{2}$ fraction in the inlet air, and $23.1 \%$ refers to the mass fraction of $\mathrm{O}_{2}$ fraction in the inlet air.

In order to calculate the amount of nitrogen $\left(\mathrm{N}_{2}\right)$ in flue gas, it is necessary to calculate how much oxygen is necessary for complete combustion, which can be done using Eq. (5).

$$
m_{O 2}=\left[a \cdot\left(1-m_{H 2 O}\right) \cdot M_{O 2} \cdot\left(\frac{m_{C}}{M_{C}}+\frac{0.5 m_{H 2}}{M_{H 2}}\right)\right]-m_{O, d r y},
$$

where $m_{O, d r y}$ is oxygen content in dry fuel $(\mathrm{kg} / \mathrm{kg})$. 
The amount of oxygen in flue gases $m_{f g, O 2}(\mathrm{~kg} / \mathrm{kg})$ after the combustion of $1 \mathrm{~kg}$ of fuel can be determined by Eq. (6).

$$
m_{f g O 2}=(a-1) \cdot m_{O 2}
$$

To determine the amount of nitrogen $m_{f g, N 2}(\mathrm{~kg} / \mathrm{kg})$ in flue gases after the combustion of $1 \mathrm{~kg}$ of fuel, Eq. (7) is used. In Eq. (7), 75.5\% refers to the mass fraction of dinitrogen in the inlet air. $1 \%$ of inertia gases in air is considered insignificant for flue gas mass flow.

$$
m_{f g, N 2}=m_{O 2} \cdot \frac{75.5 \%}{23.1 \%}+m_{N, d r y} \cdot\left(1-m_{H 2 O}\right)
$$

The amount of dry flue gas can be determined by adding all dry flue gas components (Eq. (8)).

$$
m_{f g . d r y}=m_{f g, C O 2}+m_{f g, N 2}+m_{f g, O 2}
$$

The amount of water vapours in flue gas before FGC $m_{f g l, H 2 O}$ depends on fuel moisture and hydrogen content in dry fuel. The specific amount of water vapours in flue gas is determined by Eq. (9).

$$
m_{f g 1, H 2 O}=\left(1-m_{H 2 O}\right) \cdot m_{H, d r y} \cdot \frac{M_{H 2 O}}{M_{H 2}}+m_{H 2 O}
$$

To determine $m_{f g 2, H 2 O}(\mathrm{~kg} / \mathrm{kg})$ a psychrometric chart of dew point (Fig. 1) can be used, as Fig. 1 shows the saturating amount of water vapour in dry flue gases $x\left(\mathrm{~kg}_{\mathrm{H} 2 \mathrm{O}} / \mathrm{kg}_{\mathrm{dry}}\right.$ gas $)$.

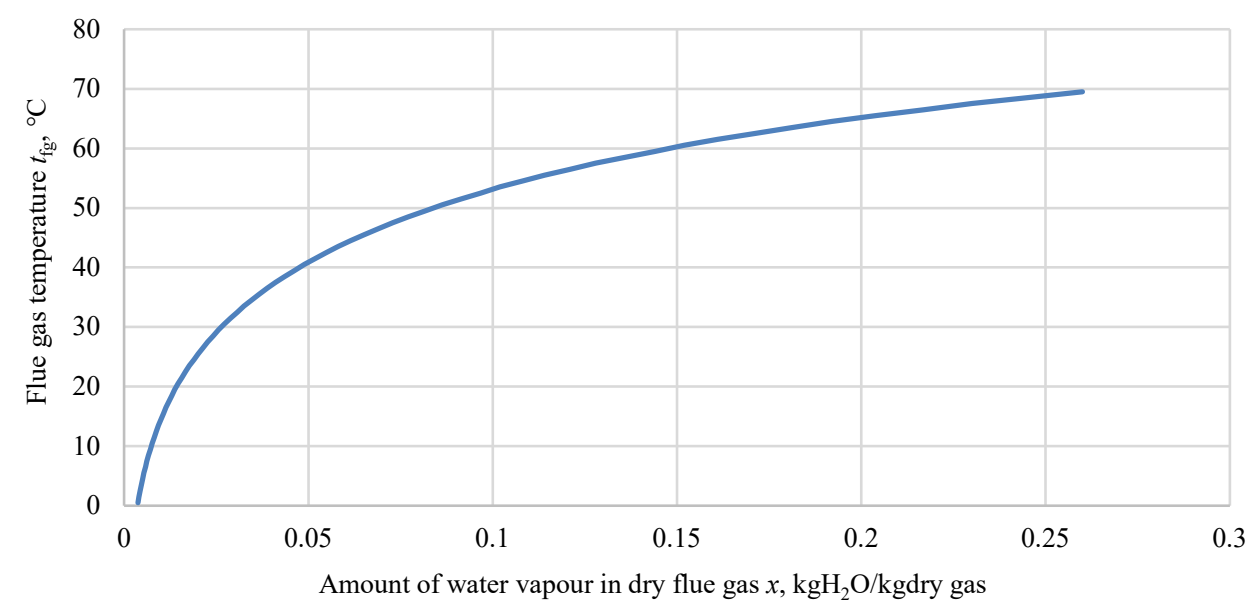

Fig. 1. Saturating amount of water vapour $\mathrm{kg}_{\mathrm{H} 2 \mathrm{O}} / \mathrm{kg}_{\text {gas }}$ from $0{ }^{\circ} \mathrm{C} \ldots 70{ }^{\circ} \mathrm{C}$ at normal pressure.

To find $m_{f g 2, H 2 O}$ Eq. (10) can be used.

$$
m_{f g, H 2 O}=m_{f g, d r y} \cdot x
$$


$2020 / 24$

The water vapour content in the gas decreases as flue gas cools down in FGC. The lower the cooling temperature, the more water can be condensed, as saturating amount of water vapour decreases. The temperature of the FGC exhaust gas is the same as the dew point temperature. Since the relative humidity of outgoing gases is $100 \%$ then Eq. (10) is valid. This leads to conclusion that when the cooling temperature is lower, more water can be condensed and more heat can be recovered. In FGC, the outgoing gases are cooled down to the district heating return temperature $t_{\text {return }}\left({ }^{\circ} \mathrm{C}\right)$. To find the mass flow rate of flue gases, $m_{f g l, H 2 O}, m_{f g 2, H 2 O}$ and $m_{f g, d r y}$ must be multiplied by boiler fuel consumption $b$.

The amount of total recovered heat $Q_{\text {rec.heat }}(\mathrm{W})$ depends on heat and mass transfer in the FGC. The energy balance in the FGC is shown in Eq. (11).

$$
Q_{\text {cond }}=Q_{\text {rec.heat }}+Q_{\text {loses }}
$$

As was mentioned before, FGC can be viewed as a heat exchanger, so the amount of total recovered heat $Q_{\text {rec.heat }}$ can be calculated similarly to the heat flux $q\left(\mathrm{~W} / \mathrm{m}^{2}\right)$ transferred through a heat exchanger with a surface $A\left(\mathrm{~m}^{2}\right)$ (Eq. (12)).

$$
Q_{\text {rec.heat }}=A \cdot q
$$

For flat heat transfer surfaces, Eq. (13) is used.

$$
q_{\text {flat }}=\frac{\Delta t_{\log }}{\frac{1}{h_{1}}+\frac{\delta}{k}+\frac{1}{h_{2}}}
$$

In Eq. (13), index 1 refers to heat transfer from flue gases to the wall of the condenser, index 2 refers to heat transfer from the condenser wall to cooling water.

As FGCs have usually tubular structure then linear heat flux $(\mathrm{W} / \mathrm{m})$ for cylinder heat transfer surfaces must be used (Eq. (14)).

$$
q_{c y l}=\frac{\pi \cdot \Delta t_{\log }}{\frac{1}{h_{1} \cdot d_{1}}+\frac{\delta}{2 k} \ln \left(\frac{d_{2}}{d_{1}}\right)+\frac{1}{h_{2} \cdot d_{2}}}
$$

In Eq. (14), index 1 refers to the inside diameter of the cylinder and heat transfer from inside the cylinder to the inner surface. Index 2 refers to the outer diameter of the cylinder and heat transfer from the outer surface of the cylinder to the environment. $\Delta t_{\log }$ can be found by Eq. (15).

$$
\Delta t_{\text {log }}=\frac{\Delta t_{f g}-\Delta t_{r e t u r n}}{\ln \frac{\Delta t_{f g}}{\Delta t_{\text {return }}}}
$$

The difference between the flue gas temperature after FGC and DH return temperature is minor, so these temperatures can be considered equal.

The decrease in temperature of the $\mathrm{DH}$ return water $\Delta t_{\text {return }}(\mathrm{K})$ can be determined by Eq. (16). 


$$
\Delta t_{\text {return }}=\frac{Q_{\text {cond }}}{c_{p, \text { return }} \cdot G_{\text {return }}}
$$

It is important to evaluate heat and mass transfer processes in a condenser, as these processes occur simultaneously. The processes that affect heat and mass transfer in FGC are: convection, conduction, heat transfer by radiation, absorption, evaporation, and condensation [27]. In this study radiation, absorption and evaporation are considered to have minimal effect in heat and mass transfer processes in FGC, so these processes are neglected. The estimation of heat and mass transfer coefficients is important for determining FGC capacity. The coefficients include thermal conductivities of the construction materials, heat carriers, and heat and mass transfer effects, such as flow velocity and regime (laminar or turbulent).

Heat transfer in FGC is depicted in Fig. 2.

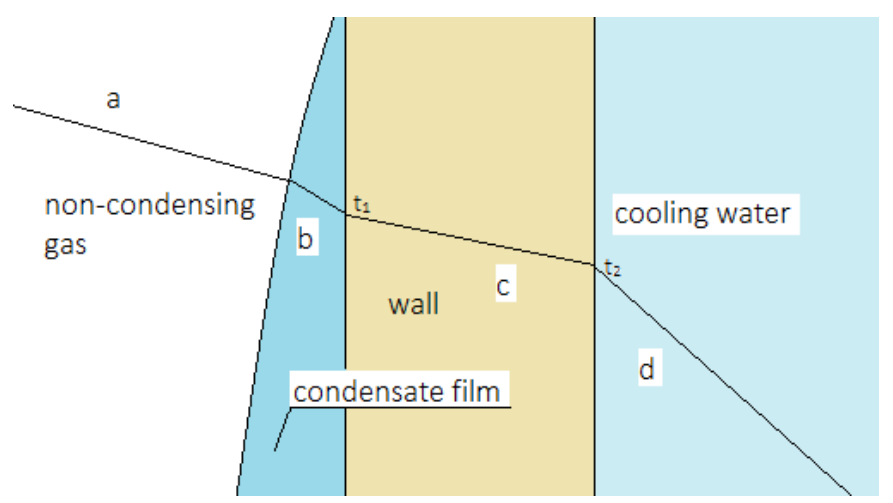

Fig. 2. Heat transfer in FGC. a - heat transfer of sensible heat of non-condensable gases; $b$ - thermal conduction through condensate film; $\mathrm{c}$ - thermal conduction through wall; $\mathrm{d}$ - convective heat transfer from wall to cooling water.

Colburn and Hougen noted that during the condensation of vapours from their admixture of non-condensable gases, the properties of the gas stream vary greatly as the vapour is removed [28]. As for FGC, the wall temperature is lower than the dew point temperature, which means that part of the vapour condenses and forms a thin liquid film on the walls [29]. This must be considered when calculating $h_{1}\left[\mathrm{~J} /\left(\mathrm{m}^{2} \cdot \mathrm{K}\right)\right]$ in Eq. (17). The Nusselt's analogy can be used for condensation heat transfer. For non-condensable gases, heat transfer can be viewed as steam diffusion through the non-condensable gas [30]. The total $h_{1}$ from Eq. (13) and (14) can be calculated as follows (Eq. (17)):

$$
h_{1}=\frac{1}{\frac{1}{h_{N u}}+\frac{1}{h_{D}}},
$$

where heat transfer coefficient $h_{N u}\left[\mathrm{~W} /\left(\mathrm{m}^{2} \cdot \mathrm{K}\right)\right]$ for a vertical wall with a height $H(\mathrm{~m})$ can be found by Eq. (18) [31].

$$
h_{N u}=0.943 \cdot \sqrt[4]{\frac{g \cdot r \cdot \rho \cdot k^{3}}{v \cdot H \cdot\left(t_{d p}-t_{\text {return }}\right)}}
$$


The dew point temperature $t_{d p}$ in Eq. (18) and (19) is the psychrometric dew point temperature for the water vapour fraction for flue gases entering the FGC.

The heat transfer coefficient $h_{D}\left[\mathrm{~W} /\left(\mathrm{m}^{2} \cdot \mathrm{K}\right)\right]$ can be calculated by Eq. (19) [32].

$$
h_{D}=\frac{t_{f g}-t_{d p}}{h_{1}\left(t_{f g}-t_{d p}\right)+r \cdot j}
$$

Eq. (17) and (19) show that an iterative method is necessary to calculate $h_{1}$ and $h_{D}$.

As for $h_{2}\left[\mathrm{~W} /\left(\mathrm{m}^{2} \cdot \mathrm{K}\right)\right]$ from Eq. (13), it can be determined as convective heat transfer Eq. (20) [31]:

$$
h_{2}=\frac{N u \cdot k_{w}}{l},
$$

where the average Nusselt number $N u$ of the flow depends on the flow regime of the cooling water.

The Reynolds number of the cooling water (DH return water) flow in the FGC can be estimated considering FGC design and cooling water flow rate.

For laminar flow $\left(\operatorname{Re}<10^{5}\right)$ Eq. (21) is applied [32].

$$
N u=0.67 \cdot \operatorname{Re}^{0.5} \cdot \operatorname{Pr}_{\text {flow }}^{0.33} \cdot\left(\frac{\operatorname{Pr}_{\text {flow }}}{\operatorname{Pr}_{\text {wall }}}\right)^{0.25}
$$

For turbulent flow $\left(\operatorname{Re}>10^{5}\right)$ Eq. (22) is applied [32].

$$
N u=0.037 \cdot \mathrm{Re}^{0.8} \cdot \operatorname{Pr}_{\text {flow }}^{0.33} \cdot\left(\frac{\operatorname{Pr}_{\text {flow }}}{\operatorname{Pr}_{\text {wall }}}\right)^{0.25}
$$

The Prandtl number $P r$ in Eq. (21) and Eq. (22) can be determined according to flow temperatures. The Prandtl number with the index flow must be determined based on the average cooling water flow temperature; the Prandtl number with the index wall refers to the Prandtl number for flowing water near the wall, where the water temperature is approximately equal to the wall temperature.

The wall temperature, which is mandatory for determining the Prandtl number near the wall, can be found by Eq. (23) and Eq. (24) [31].

For a flat wall:

$$
t_{\text {wall }, \text { flat }}=t_{\text {return }}+\frac{1}{h_{2}} \cdot \frac{t_{f g}-t_{\text {return }}}{\frac{1}{h_{1}}+\frac{\delta}{k}+\frac{1}{h_{2}}} .
$$

For a cylinder wall:

$$
t_{\text {wall }, \text { cyl }}=t_{\text {return }}+\frac{q_{c y l}}{\pi} \cdot\left[\frac{1}{h_{1} \cdot d_{1}}+\frac{1}{2 k} \ln \left(\frac{d_{2}}{d_{1}}\right)\right] .
$$

Iterative method must be used to determine the wall temperature. FGC efficiency can be calculated by Eq. (25). 


$$
\eta_{F G C}=\frac{Q_{\text {rec.heat }}}{Q_{\text {cond }}}
$$

PES for $1 \mathrm{MWh}$ are directly related to FGC recovered heat $Q_{\text {rec. heat }}$, and also considering the heat that enters the boiler with the combustion air $Q_{\text {air }}(\mathrm{W})$, and the heat that is used for heating the components in the boiler $Q_{c o m p}(\mathrm{~W}) . P E S_{I M W h}(\mathrm{MWh} / \mathrm{MWh})$ can be calculated by Eq. (26).

$$
P E S_{I M W h}=\frac{Q_{F G C}-Q_{\text {air }}-Q_{\text {comp }}}{Q}
$$

As for the PES increase potential $P E S_{\text {inc }}$ for the DH return temperature reduction by $1{ }^{\circ} \mathrm{C}$, Eq. (27) can be used.

$$
P E S_{\text {inc }}=\frac{\Delta P E S_{1 M W h}}{\Delta t_{\text {return }}}
$$

\section{Model Approbation}

To validate the model, the results were compared with real measurements obtained at the Mustamäe Combined-Heat-and-Power Plant, which was launched in 2019. The parameters used as input data for the model are listed in Table 1.

The following indicators were calculated: heat recovery, FGC efficiency and primary energy savings. To compare the results obtained using the methodology described in the previous section and operational data, the following parameters were measured over the period of September 16, 2019 - December 5, 2019; heat recovery, flue gas supply and return temperature, fuel moisture content, overall thermal power of the plant and DH return temperature. Both the calculated and measured results are shown in Fig. 3. The design capacity of the FGC at the Mustamäe CHP is $9 \mathrm{MW}$.

TABle 1. Calculation Parameters

\begin{tabular}{ll}
\hline Parameter & Value \\
\hline Flue gas temperature $t_{f g}$ & $162.34{ }^{\circ} \mathrm{C}$ \\
Boiler output power $Q$ & $44.1 \mathrm{MW}$ \\
Fuel & woodchips \\
FGC gas flow Reynolds number Re & 5000 \\
Heat transfer surface area $A$ & $56 \mathrm{~m}^{2}$ \\
Water flow through FGC $G$ & $215.79 \mathrm{~kg} / \mathrm{s}$ \\
Thermal conductivity of the heat exchanger wall $k$ & $0.399 \mathrm{~kW} /(\mathrm{m} \cdot \mathrm{K})$ \\
Fuel gross calorific value $Q_{G C V}$ & $19.94 \mathrm{MJ} / \mathrm{kg}$ \\
Median fuel moisture content $m_{H 2 O}$ & $0.39 \mathrm{~kg} / \mathrm{kg}$ \\
Dry fuel carbon content $m_{C, d r y}$ & $0.500 \mathrm{~kg} / \mathrm{kg}$ \\
Dry fuel hydrogen content $m_{H, d r y}$ & $0.065 \mathrm{~kg} / \mathrm{kg}$ \\
Dry fuel oxygen content $m_{O, d r y}$ & $0.400 \mathrm{~kg} / \mathrm{kg}$ \\
Excess air coefficient $a$ & 1.05 \\
\hline
\end{tabular}




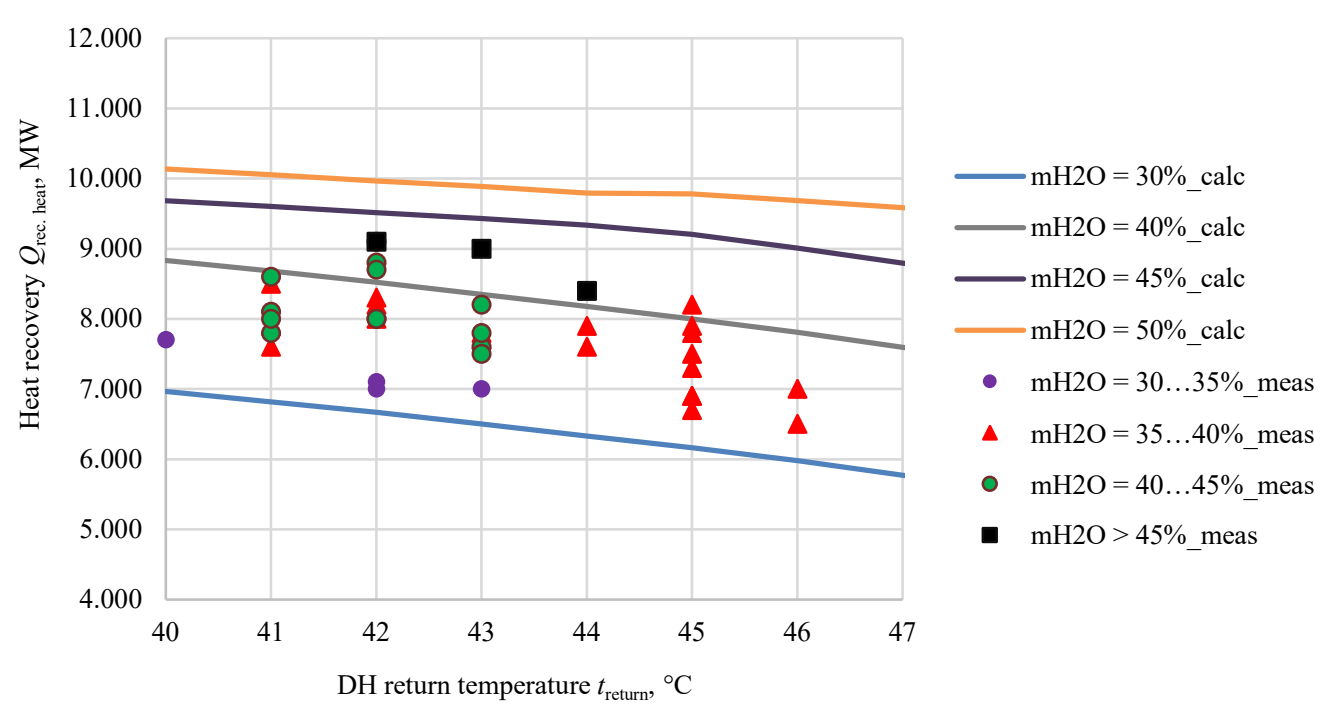

Fig. 1. Measured and calculated results, Mustamäe CHP.

The average relative difference between the measured and calculated results is $4.3 \%$. Relative difference $r d$ can be found by Eq. (28).

$$
r d=\frac{\left|Q_{\text {rec.heat.meas. }}-Q_{\text {rec.heat.calc. }}\right|}{Q_{\text {rec.heat.meas. }}}
$$

The problem with the fuel moisture content in this theoretical model is that although power plants measure the moisture content of each load of fuel, it is still unclear when the load is going to be incinerated. There is a tendency that the loads of woodchips that are delivered to the plant on weekdays will be used the next day.

The FGC recovered heat is used to pre-heat water, therefore it is added to the boiler heat output to determine the plant's overall thermal power. Since the FGC recovered heat depends on the return temperature, the overall thermal efficiency of the plant is also related to the $\mathrm{DH}$ return temperature. The DH return temperature also affects efficiency of the FGC. This can be explained by the FGC's heat exchanger properties: like a heat exchanger, FGC also has a certain heat capacity which is determined by heat transfer area $A$ (Eq. (11)) and other constructional properties (flat or cylinder surfaces, surface thickness, materials, etc.). This leads to the conclusion that when the condensation heat $Q_{\text {cond }}$ reaches the FGC's design capacity, lowering the $\mathrm{DH}$ return temperature will not increase the amount of recovered heat. The correlation between the FGC efficiency and the DH return temperature is illustrated in Fig. 4. The data presented in Fig. 4 was calculated using the parameters listed in Table 1, which are also the average operational parameters of the observed case. 


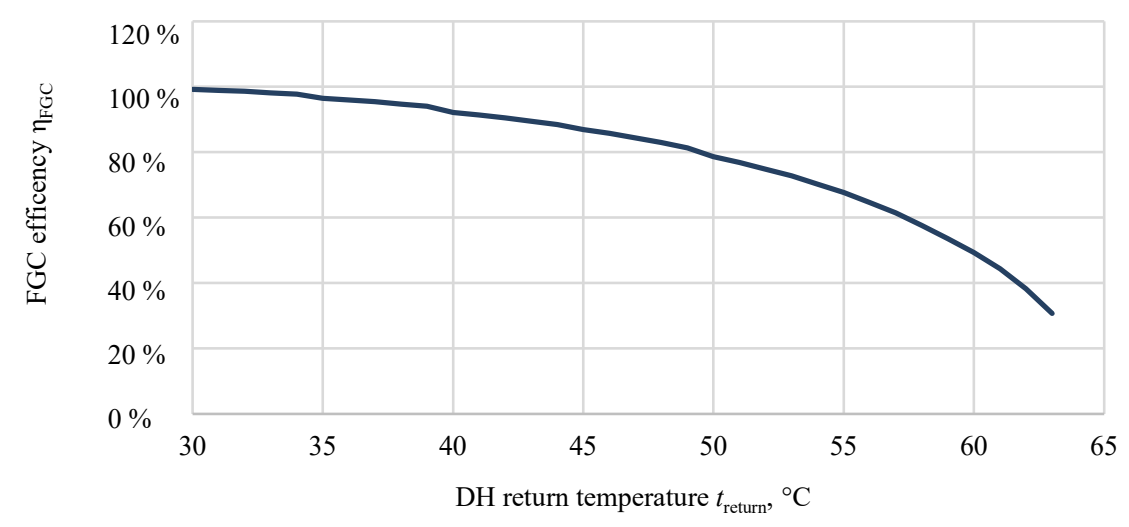

Fig. 4. FGC efficiency at different DH return temperatures.

The potential for increased heat recovery with FGC is greater when DH return temperatures are higher. This can be seen in Fig. 5. The calculations for Fig. 5 were also made using the data from Table 1.

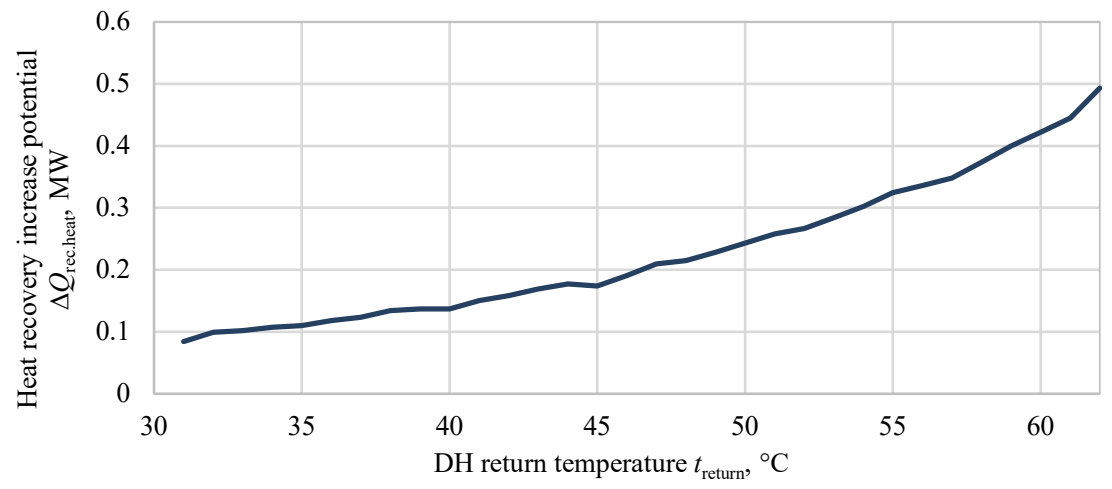

Fig. 5. Heat recovery increase potential when the $\mathrm{DH}$ return temperature is reduced by $1{ }^{\circ} \mathrm{C}$ at different $\mathrm{DH}$ return temperatures.

Since the average moisture content of woodchips is $40 \%$, then the NCV of woodchips is $10.3 \mathrm{MJ} / \mathrm{kg}$. Therefore, $349.2 \mathrm{~kg}$ of woodchips are required to produce $1 \mathrm{MWh}$ of thermal energy when condensation heat is not used. When condensation heat is used to produce thermal energy, fuel consumption can be reduced. Since the DH return temperature decreases, the FGC recovered heat increases, therefore reducing the $\mathrm{DH}$ return temperature also decreases boiler fuel consumption which leads to PES. Fig. 6 illustrates PES potential per $1 \mathrm{MWh}$, when the DH return temperature is reduced by $1^{\circ} \mathrm{C}$. The PES potential is greater at higher temperatures. When the temperature drops below $40{ }^{\circ} \mathrm{C}$, further reduction will bring about $2 \mathrm{kWh} /(\mathrm{MWh} \cdot \mathrm{K}) \mathrm{PES}$, which is about $1 \mathrm{~kg}$ of woodchips per MWh produced. 


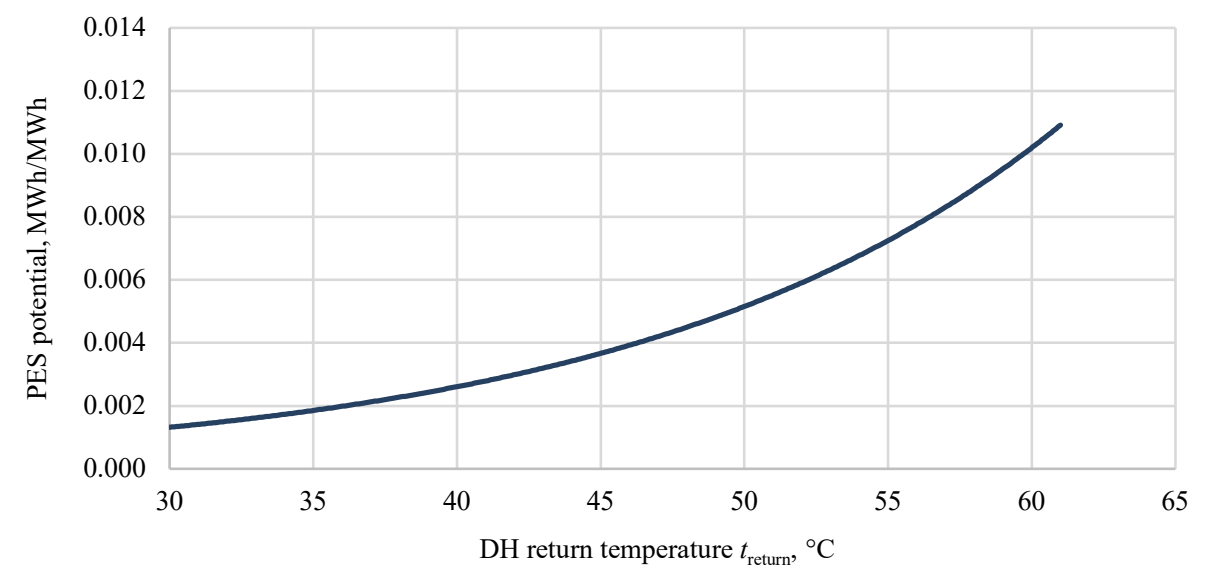

Fig. 6. PES increase potential per $1 \mathrm{MWh}$ with $\mathrm{DH}$ return temperature reduction by $1{ }^{\circ} \mathrm{C}$ at different $\mathrm{DH}$ return temperatures.

The main possibility of DH return temperature reduction for examined CHP is adding new low-temperature consumers to DH network and also refurbishment of existing consumers.

\section{Conclusions}

The aim of this study was to evaluate the effect of low DH return temperatures on the FGC efficiency. The methodology was based on FGC heat recovery calculations, that determine the amount of sensible and latent heat in flue gases and considering also heat and mass transfer processes in FGC. There are other methodologies that can also be used to assess the impact of the return temperature impact on the FGC efficiency, but the advantage of the method proposed in this study is that this method is more flexible and it is not based on one specific construction model. Due to this advantage, the model developed in this study can also be used to calculate the profitability of the FGC installation, if DH temperatures and boiler capacities are known. The model can also be used in preparing the FGC installation at a boiler house or CHP to calculate the necessary capacity of the FGC. This model can also estimate the minimum profitable temperature for various fuels with different moisture content. In addition, the proposed method includes tools for PES increase potential.

The amount of flue gas that is mentioned in this study can also be found using DIN EN 12952-15 standard. However, flue gas estimation method proposed in this study is more versatile and can be applied to various types of fuels because physical constants, such as molar mass, chemical reaction coefficients, and specific heat are used instead of numerical constants. The choice to use either method does not affect the results.

The input parameters of the new Mustamäe CHP were used for model approbation. Additionally, operational data was collected at the CHP and compared with the calculated parameters.

The following parameters were calculated: the amount of FGC-recovered heat $Q_{\text {rec,heat,calc }}$, FGC efficiency $\eta_{F G C}$, and PES potential per $1 \mathrm{MWh} P E S_{I M W h}$.

The following parameters were measured: the DH return temperature $t_{\text {return }}$, the amount of FGC-recovered heat $Q_{\text {rec, heat,meas, }}$, total thermal output of the boiler $Q$, flue gas temperature $t_{f g}$, fuel moisture content $m_{H 2 O}$, and dry fuel analytical content. 
Both the results of the modelling and measurements confirm that the reduction of the DH return temperature has a positive effect on the FGC efficiency, since the reduction of DH return temperatures increases efficiency and the amount of FGC-recovered heat. FGC can provide significant PES when used with boilers that use high-moisture fuel, such as woodchips.

Unfortunately, due to the warm winter, the range of DH return temperatures $t_{\text {return }}$ that were measured is very limited. Nevertheless, the measured and calculated results coincide, and this trend is obvious.

DH producers will benefit directly from an increase in the FGC efficiency. Since fuel costs can be reduced as a result, this can have a positive effect on the price of $\mathrm{DH}$, since lowering the return temperature affects the amount of FGC-recovered heat. The specific PES for various DH return temperatures was evaluated, and it turned out that the PES potential by reducing DH return temperature is exceptional when $\mathrm{DH}$ return temperatures are high. When $\mathrm{DH}$ return temperatures drop below $40{ }^{\circ} \mathrm{C}$, further temperature reduction will not increase the potential of PES.

\section{REFERENCES}

[1] European Parliament Council of the European Union. Directive 2012/27/EU of the European Parliament and of the Council of 25 October 2012 on energy efficiency, amending Directives 2009/125/EC and 2010/30/EU and repealing Directives 2004/8/EC and 2006/32/EC Text with EEA relevance. Official journal of the European Union 2012:L 315/1.

[2] European Parliament Council of the European Union. Directive 2012/27/EU of the European Parliament and of the Council of 25 October 2012. Official journal of the European Union. https://doi:10.3000/19770677.L_2012.315.eng

[3] Volkova A., Mašatin V., Siirde A. Methodology for evaluating the transition process dynamics towards 4th generation district heating networks. Energy 2018:150:253-261. https://doi.org/10.1016/j.energy.2018.02.123

[4] Köfinger M., Basciotti D., Schmidt R. R. Reduction of return temperatures in urban district heating systems by the implementation of energy-cascades. Energy Procedia 2017:116:438-451.

https://doi.org/10.1016/j.egypro.2017.05.091

[5] Feofilovs M., Pakere I., Romagnoli F. Life Cycle Assessment of Different Low-Temperature District Heating Development Scenarios: A Case Study of Municipality in Latvia. Environmental and Climate Technologies 2019:23(2):272-290. https://doi.org/10.2478/rtuect-2019-0068

[6] Pakere I., Blumberga D. Solar Energy in Low Temperature District Heating. Environmental and Climate Technologies 2019:23(3):147-158. https://doi.org/10.2478/rtuect-2019-0085

[7] Polikarpova I., Lauka D., Blumberga D., Vigants E. Multi - Criteria Analysis to Select Renewable Energy Solution for District Heating System. Environmental and Climate Technologies 2019:23(3):101-109. https://doi.org/10.2478/rtuect-2019-0082

[8] Pieper H., Volkova A., Mašatin V. Large-scale heat pump integration model: A case study of Tallinn district heating. 4th Int. Conf. Smart Energy Syst. 4th Gener. Dist. Heating, Aalborg, Denmark, 2018.

[9] Nardecchia F., et al. An alternative tool for the energy evaluation and the management of thermal networks: The exergy analysis. EEEIC 2016:1-6. https://doi.org/10.1109/EEEIC.2016.7555645

[10] Karkaba H., Habchi C., Al Takash A. Numerical Analysis of Different Indoor Heating Methods. Proceeding of the 4th International Conference Advanced Computer Tools Engineering Applications (ACTEA) 2019:1-7. https://doi.org/10.1109/ACTEA.2019.8851075

[11] Guelpa E., Marincioni L. Demand side management in district heating systems by innovative control. Energy 2019:188:116037. https://doi.org/10.1016/j.energy.2019.116037

[12] Latõšov E., et al. The Impact of Parallel Energy Consumption on the District Heating Networks. Environmental and Climate Technologies 2019:23(1):1-13. https://doi.org/10.2478/rtuect-2019-0001

[13] Brand M., Svendsen S. Renewable-based low-temperature district heating for existing buildings in various stages of refurbishment. Energy 2013:62:311-319. https://doi.org/10.1016/j.energy.2013.09.027

[14] Volkova A., et al. Energy cascade connection of a low-temperature district heating network to the return line of a hightemperature district heating network. Energy 2020:198:117304. https://doi.org/10.1016/j.energy.2020.117304

[15] Ziemele J., et al. Sustainability of heat energy tariff in district heating system: Statistic and dynamic methodologies. Energy 2017:137:834-845. https://doi.org/10.1016/j.energy.2017.04.130 
[16] Galindo Fernández M., et al. Efficient district heating and cooling systems in the EU Case studies analysis, replicable key success factors and potential policy implications. Luxembourg: Publications Office of the European Union, 2016. https://doi.org/10.2760/371045

[17] AS Narva Soojusvõrk. Technical report. 2019.

[18] Blumberga D., et al. Empirical Model of Cost Reduction in Local DH Systems Low Temperature Approach. Environmental and Climate Technologies 2019:23(3):190-201. https://doi.org/10.2478/rtuect-2019-0089

[19] Vigants G., et al. Cost Analysis of a Wood Chip Boiler House with a Gas Condenser. Energy Procedia 2015:75:1214 1220. https://doi.org/10.1016/j.egypro.2015.07.159

[20] Priedniece V., et al. Experimental and analytical study of the flue gas condenser - fog unit. Energy Procedia 2019:158:822-827. https://doi.org/10.1016/j.egypro.2019.01.215

[21] Soleimanikutanaei S., Lin C.X., Wang D. Numerical modeling and analysis of Transport Membrane Condensers for waste heat and water recovery from flue gas. International Journal of Thermal Sciences 2019:136:96-106. https://doi.org/10.1016/j.ijthermalsci.2018.10.014

[22] Vannoni A., Sorce A., Bosser S., Buddenberg T. Heat recovery from Combined Cycle Power Plants for Heat Pumps. E3S Web Conference 2019:113:1-9. https://doi.org/10.1051/e3sconf/201911301011

[23] Striūgas N., et al. Estimating the fuel moisture content to control the reciprocating grate furnace firing wet woody biomass. Energy Conversion Management 2017:149:937-949. https://doi.org/10.1016/j.enconman.2017.04.014

[24] Paraschiv L. S., Serban A., Paraschiv S. Calculation of combustion air required for burning solid fuels (coal / biomass / solid waste) and analysis of flue gas composition. Energy Reports 2019:6:36-45. https://doi.org/10.1016/j.egyr.2019.10.016

[25] European Standards, DIN EN 12952-15:2003. Water-tube boilers and auxiliary installations - Part 15: Acceptance tests. 2003.

[26] Li P.W., Chyang C.S. A comprehensive study on NOx emission and fuel nitrogen conversion of solid biomass in bubbling fluidized beds under staged combustion. Journal of the Energy Institute 2019:93:324-334. https://doi.org/10.1016/j.joei.2019.02.007

[27] Kuznetsov G. V., et al. Mechanism of Sulfur and Nitrogen Oxides Suppression in Combustion Products of Mixed Fuels Based on Coal and Wood. Combustion Science and Technology 2019:191(11):2071-2081. https://doi.org/10.1080/00102202.2018.1543285

[28] Blumberga D., Vigants E., Veidenbergs I. Analysis of flue gas condenser operation. Latvian Journal of Physics and Technical Science 2011:48(4):58-65. https://doi.org/10.2478/v10047-011-0028-3

[29] Colburn A. P., Hougen O. A. Design of Cooler Condensers for Mixtures of Vapors with Noncondensing Gases. Industrial Engineering and Chemistry 1934:26:1178-1182. https://doi.org/10.1021/ie50299a011

[30] Jia L., et al. Effects of water vapor condensation on the convection heat transfer of wet flue gas in a vertical tube. Int. J. Heat \& Mass Transfer 2001:44(22):4257-4265. https://doi.org/10.1016/S0017-9310(01)00082-5

[31] Jeong K., et al. J., Analytical modeling of water condensation in condensing heat exchanger. International Journal of Heat and Mass Transfer 2010:53(11-12):2361-2368. https://doi.org/10.1016/j.ijheatmasstransfer.2010.02.004

[32] Käär H., et al. Soojus- ja massilevi. I osa. Põhikursus. (Heat and mass transfer. Part I. Basic course.) Tallinn: Tallinn University of Technology, 1998. (in Estonian)

[33] Poobus A., Tiikma T. Soojus- ja massilevi II. (Heat and mass transfer. Part II.) Tallinn: Tallinn University of Technology, 2000. 